\title{
Differential Effect of Light and Dark Period Sleep Fragmentation on Composition of Gut Microbiome and Inflammation in Mice
}

\author{
Larry D. Sanford ${ }^{1, *}$, Laurie L. Wellman ${ }^{1}{ }^{(\mathbb{D}}$, Richard P. Ciavarra ${ }^{2}$, Edward C. Oldfield IV ${ }^{3}$, Rouzbeh Shams ${ }^{3}$, \\ Jennifer L. Copare ${ }^{3}$ and David A. Johnson ${ }^{3}$ \\ 1 Sleep Research Laboratory, Center for Integrative Neuroscience and Inflammatory Diseases, \\ Pathology and Anatomy, Eastern Virginia Medical School, Norfolk, VA 23507, USA; Wellmall@evms.edu \\ 2 Microbiology and Molecular Cell Biology, Eastern Virginia Medical School, Norfolk, VA 23507, USA; \\ ciavarrp@evms.edu \\ 3 Gastroenterology Division, Department of Internal Medicine, Eastern Virginia Medical School, \\ Norfolk, VA 23507, USA; ecoldfield@gmail.com (E.C.O.IV); rouzbehshams@gmail.com (R.S.); \\ jencopare@gmail.com (J.L.C.); dajevms@aol.com (D.A.J.) \\ * Correspondence: Sanforld@EVMS.EDU; Tel.: +1-757-446-7081
}

check for updates

Citation: Sanford, L.D.; Wellman, L.L.; Ciavarra, R.P.; Oldfield, E.C., IV; Shams, R.; Copare, J.L.; Johnson, D.A. Differential Effect of Light and Dark Period Sleep Fragmentation on Composition of Gut Microbiome and Inflammation in Mice. Life 2021, 11, 1283. https://doi.org/10.3390/ life11121283

Academic Editor: Manuela Marcoli

Received: 20 October 2021

Accepted: 19 November 2021

Published: 23 November 2021

Publisher's Note: MDPI stays neutral with regard to jurisdictional claims in published maps and institutional affiliations.

Copyright: (c) 2021 by the authors. Licensee MDPI, Basel, Switzerland. This article is an open access article distributed under the terms and conditions of the Creative Commons Attribution (CC BY) license (https:/ / creativecommons.org/licenses/by/ $4.0 /)$.

\begin{abstract}
Bi-directional interactions amongst the gut microbiota, immune system, and brain function are thought to be critical mediators of health and disease. The role sleep plays in mediating these interactions is not known. We assessed the effects of sleep fragmentation (SF) on the microbiotagut-brain axis. Male C57BL/6NCrl mice (4 to 5 per cage, fed standard lab chow) experienced SF via mechanical stimulation at 2 min intervals during the light (SF) and dark (DD, dark disturbances) periods. Home cage (HC) controls were undisturbed. After 10 days, fecal samples were collected at light onset, midday, light offset, and midnight. Samples were also collected after 10 days without SF. Subsequently, the mice were randomized across groups and allowed 20 additional days of recovery followed by 10 days of SF or DD. To assess effects on the microbiota, 16S rRNA sequencing was used, and mesenteric lymph nodes (MLNs) and cortex and medial prefrontal cortex were analyzed using cytokine arrays. SF and DD produced significant alterations in the microbiota compared to HC, and DD had greater impact than SF on some organisms. SF produced marked suppression in MLNs of chemokines that regulate inflammation (CCL3, CCL4 and their receptor CCR5) and maintain the immune mucosal barrier (Cxcl13) at the same time that cortical cytokines (IL-33) indicated neuroinflammation. DD effects on immune responses were similar to HC. These data suggest that SF alters the microbiome and suppresses mucosal immunity at the same time that mediators of brain inflammation are upregulated. The translational implications for potential application to clinical care are compelling.
\end{abstract}

Keywords: chemokine; cytokine; immune system; microbiome; neuroinflammation

\section{Introduction}

Studies have strongly implicated the various microorganisms that inhabit and share our bodies in mediating health and disease and behavior via influences on the immune system and brain. Influences are believed to be bi-directional. For example, while gut microbiota may modulate brain function, the brain may alter gut microbiota by changing gastrointestinal motility and intestinal permeability [1,2]. There is also a potential relationship between sleep disturbances and gut microbiota that appear to have relevance for disease [3-6]. However, the effects of sleep disruption are complex as it also has a significant impact on the immune system [7-11] that would have the potential to alter the effects of the gut microbiota, possibly altering the immune processes that maintain the barrier between host tissue and the microbiota and/or functioning of the central nervous system. An extreme example of this is found in animals experiencing prolonged, experimental 
sleep deprivation. Sustained sleep deprivation promotes bacterial translocation [12], and death that can occur after prolonged sleep deprivation in animals has been attributed to bloodstream infection by opportunistic anaerobic bacteria that normally are contained within the gut [13]. Thus, while experimental prolonged sleep deprivation does not model sleep disturbances common in modern life, the recognized effects of sleep deficiency and increasing recognition of the role that the gut microbiota play in mediating immune function suggest that delineating the interactions among disturbed sleep, the immune system and gut microbiota was critical for understanding their role in health and disease.

In this study, we examined the effects of disturbed sleep on elements of the microbiotagut-brain (M-G-B) axis using a mouse model of sleep fragmentation (SF). SF disrupts the continuity of sleep and interferes with its restorative effects [7] without necessarily significantly altering total sleep time. SF is highly prevalent in modern life as it can arise from stress [14], increases with aging [15] and it is a hallmark of sleep apnea [15], a condition linked to obesity and that has been associated with a variety of health risks [15]. Critically, SF is significant because it can arise from a variety of environmental- (e.g., stressrelated), physiological- (e.g., aging) and disease-related (e.g., sleep apnea) causes that have the potential to impact health. It also has been reported to increase food intake, increase growth in Lachnospiraceae and Ruminococcaceae and decrease Lactobacillaceae families, produce systemic and visceral white adipose tissue inflammation, and to alter insulin sensitivity [16].

We examined expression of chemokines/cytokines in the mesenteric lymph nodes (MLNs) as measures of the effects on the mucosal immune response and in selected brain regions (cortex, medial prefrontal cortex (regulates stress response)) as measures of the neuroimmune response using qPCR inflammatory cytokine arrays. We also compared the effects of disruptions conducted in the light period (major sleep period of rodents) and in the dark period (when they are more active) to assess effects specific to disrupted sleep relative to those produced by forced movement during the wake period.

\section{Materials and Methods}

\subsection{Subjects}

Male C57BL/6NCrl (B6) mice were obtained from Charles River (Wilmington, MA, USA). The mice were 8-9 weeks old and weighed 20-25 g at arrival. The animals were group housed and were kept in a colony room with food (Envigo, 2014 Teklad global 14\% protein rodent maintenance diet) and water available, ad libitum. The colony room was maintained on a $12: 12$ light-dark cycle and ambient temperature at $24^{\circ} \mathrm{C} \pm 1.5^{\circ} \mathrm{C}$. At least one week for acclimation was allowed before the experiment was started. Throughout the experimental procedures, measures were taken to minimize unnecessary pain and discomfort of the animals. All procedures were conducted in accordance with the National Institutes of Health Guide for the Care and Use of Experimental Animals and were approved by Eastern Virginia Medical School's Institutional Animal Care and Use Committee (protocol 17-015, approved 15 September 2017).

\subsection{Procedures}

\subsubsection{Sleep Fragmentation and Collection of Fecal Samples}

SF was performed using a commercial, validated device (Lafayette Instruments, Sleep Fragmentation Chamber, model 80391) that employs an automated sweeper arm that moves across animal cages to disrupt sleep via tactile stimulation [7,17]. This SF protocol ( $2 \mathrm{~min}$ between each sweep) reportedly produces moderate to severe SF $[7,8,17]$ without significantly reducing overall sleep or significantly impacting sleep macro- or micro-architecture $[7,17]$. Studies have also reported that this procedure is not associated with measurable increases in stress hormones, [7,17] but can impair cognitive performance [7] and can have a negative impact on health including promoting obesity [18] and tumor formation [8].

To conduct SF, mice were housed ( $4-5$ per cage) in the SF devices. One group was subjected to SF (2 min intervals between each sweep) during the light period (normal 
sleep time). Another group received identical treatment during the dark period (DD, dark disturbance group) and another served as a home cage control with no sleep interruption (HC). After 10 days of SF or DD, fecal samples were collected at light onset, midday, light offset, and midnight. Subsequently, the mice were allowed to sleep undisturbed for an additional 10 days and fecal samples were again collected at $6 \mathrm{~h}$ intervals. Time matched samples were collected from undisturbed HC mice that never experienced SF or DD.

Fecal samples were processed using MoBio Power Mag kits (MO BIO Laboratories, Inc., Carlsbad, CA, USA). All samples were then cataloged by identifiers containing animal, group and sample period and analyzed using 16S rRNA Sequencing (conducted at the DNA Sciences Core, University of Virginia). Briefly, library preparation and sequencing were conducted on an Illumina MiSeq instrument using the Illumina 16s metagenomics protocol with $15 \%$ PhiX spike-in as control. Fastq generation and 16s riboRNA assignments were conducted using Illumina Metagenomics software. Further statistical comparisons and unsupervised clustering classification of the samples were conducted using the DNA-Chip Analyzer (dChip) software package.

\subsubsection{Sleep Fragmentation and Tissue Collection}

After completion of collecting fecal samples, the mice were randomized across groups and allowed 20 days of recovery followed by 10 additional days of SF or DD prior to sacrifice for assessment of chemokine/cytokine profiles. The mice were euthanized at the end of the last SF session and tissue was collected for analyses of chemokines/cytokines in the mesenteric lymph nodes (MLNs) as measures of the effects on the mucosal immune response and in select brain regions (cortex and medial prefrontal cortex) as measures of the neuroimmune response. RNA was purified from homogenized tissue using the QuickGene RNA tissue kit SII (RT-S2) from FUJIFILM Corporation following the manufacturer's instructions. Individual RNA samples were pooled and proinflammatory cytokine profiles characterized by real-time PCR using commercial inflammatory cytokine arrays (Qiagen, catalogue number PAMM-0150Z, Hilden, Germany). Cytokine mRNA levels from HC mice were used as controls to calculate fold differences in the experimental groups. Input RNA was normalized using house-keeping genes provided with each array.

\subsection{Statistics}

Comparisons across groups were conducted using between subjects, one-way ANOVAs. Post hoc comparisons among means, when indicated by a significant overall ANOVA, were conducted using Holm-Sidak tests (to maintain error rate at $p<0.05$ ). Treatment assignment and sampling periods were coded and blinded to investigators who performed the data preparation, sequencing and subsequent data analyses. The Shannon index was calculated and compared across groups and across treatment conditions and sample periods to assess potential effects of SF on alpha diversity of gut microbiota species.

\section{Results}

\subsection{SF and DD Produce Different Changes in Gut Microbiota}

Our studies show that both $\mathrm{SF}$ and DD altered the gut microbiome, but had different effects. As depicted in Figure 1A, SF and DD induced alterations in the circadian rhythm for total reads of all genera relative to undisturbed cohorts. Reads for selected genera after 10 days of SF, DD or time matched HC mice are presented in Figure 1B. Differences could vary across groups and with time of day, both light and DD could perturb the microbiota relative to control, and DD had a greater impact than SF on some organisms. Alpha diversity did not differ across groups or across time (Figure 1C). 

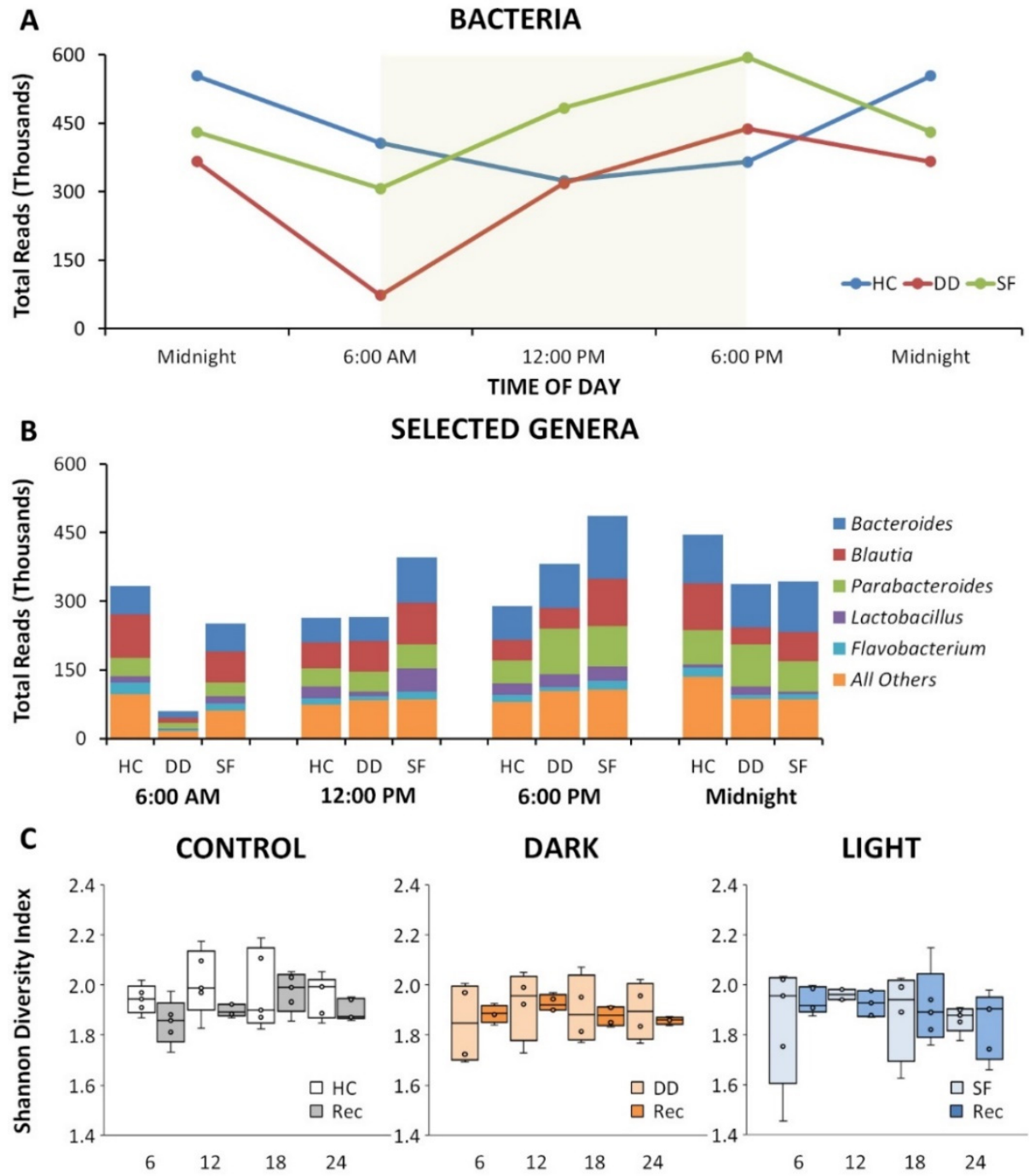

Figure 1. Sleep fragmentation (SF) alters gut microbiota. (A) Disruption of circadian microbiome pattern following SF (red) and dark disturbed (DD, blue) mice compared to home cage control (green) mice determined as total bacterial 16S RNA sequencing reads. Yellow box represents lights on in a $12 \mathrm{~h} \mathrm{ON} / 12 \mathrm{~h}$ OFF light cycle in the animal room. (B) Break-down of reads by top represented genera over the $24 \mathrm{~h}$ specimen collection time for HC, DD and SF highlighting a compelling suppression of reads following DD and the overall inversion of circadian pattern for SF. (C) Box and whisker plots of alpha diversity plotted in $6 \mathrm{~h}$ increments for HC, DD and SF groups under sleep fragmentation and recovery conditions. There was no significant change across groups or conditions.

Significant alterations were found for major phyla including Bacteriodes, Firmicutes, and Proteobacteria as well as in less prominent phyla. Differences in relative abundance at the phylum level for Bacteroidetes, Firmicutes, and Proteobacteria, and for selected families for the first 10 days are shown in Figure 2. Some microbiota continued to show differences across groups at recovery 10 days after SF had been discontinued, though many of the differences had disappeared (Figure 3). Overall group differences also varied from the experimental period where mice received SF to the recovery period after SF had ended (e.g., Flavobacteriaceae (Experimental: DD $>$ SF; DD $>$ HC, $p<0.05$; Recovery: $\mathrm{HC}>\mathrm{DD}, p<0.05$ ); Turicibacteraceae (Experimental: DD > SF; DD > HC, $p<0.05$; Recovery: $\mathrm{HC}>\mathrm{DD}, \mathrm{HC}>\mathrm{SF}, p<0.05$ ); Coriobacteriaceae (Experimental: $\mathrm{HC}>\mathrm{DD}, \mathrm{HC}>\mathrm{SF}, p<0.05$; Recovery: DD $>\mathrm{HC}$; DD $>\mathrm{SF}, p<0.05)$ ). These data demonstrate that both light and DD can significantly perturb the microbiome, and that effects can persist after SF has ended. 
Interestingly, most of the persisting effects were found in mice that had been subjected to DD.

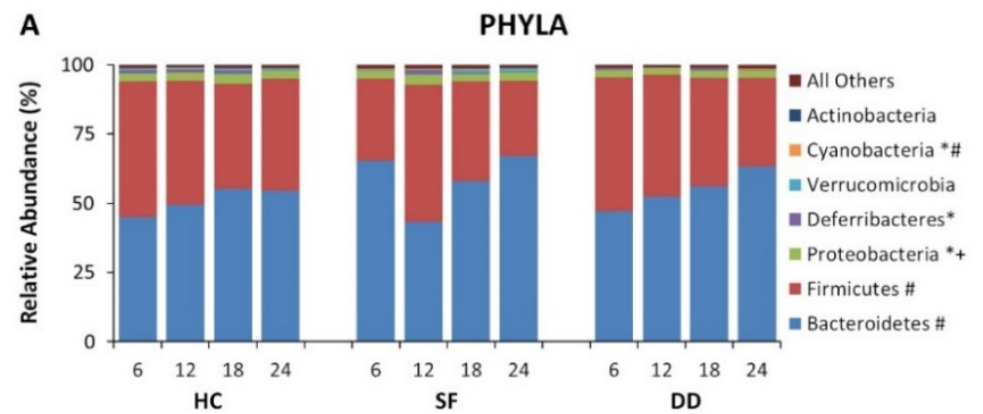

B

BACTERIODETES

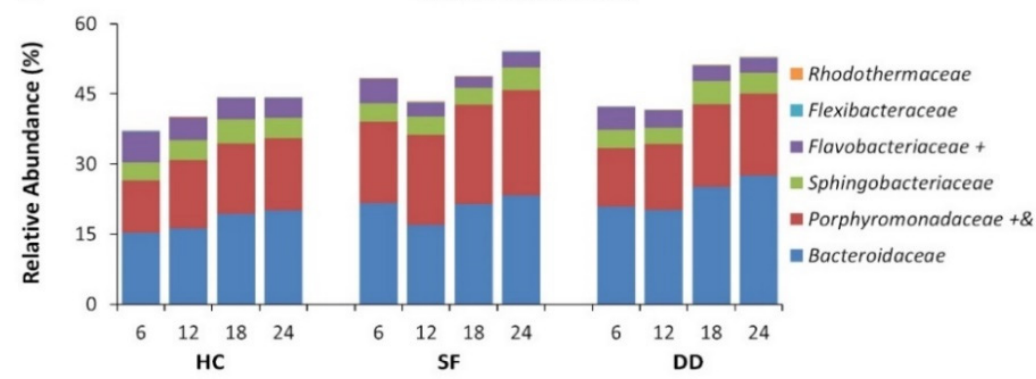

C

FIRMICUTES
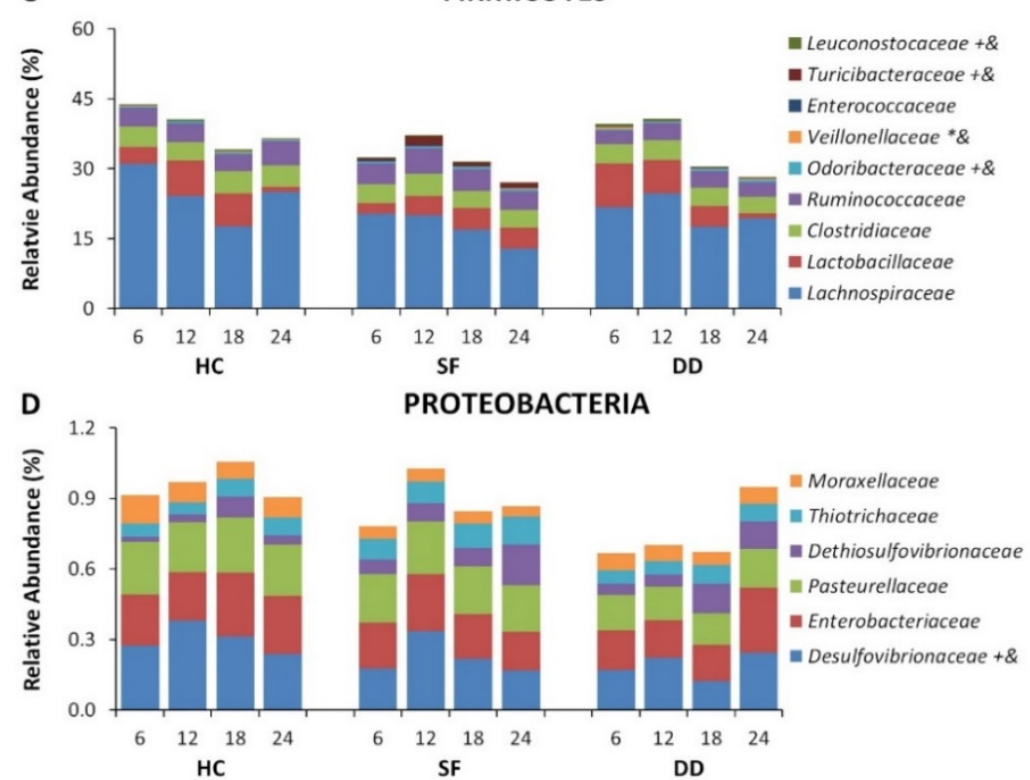

Figure 2. Relative abundance of selected microbiota for the home cage control (HC), dark disturbed (DD) and sleep fragmented (SF) experimental groups plotted at $6 \mathrm{~h}$ sampling intervals beginning at light onset. (A) Relative abundance at the phylum level. (B) Relative abundance at the family level for Bacteroidetes. (C) Relative abundance at the family level for Firmicutes. (D) Relative abundance at the family level for Proteobacteria. Significance is indicated beside the classification name: $*, p<0.05$, SF compared to control;,$+ p<0.05$ DD compared to control; \&, $p<0.05$ DD compared to SF; \#. $p<0.05$ across sampling periods (indicated only for Phyla). All Pairwise Multiple Comparison Procedures performed using the Holm-Sidak method. Data at the phylum level are shown as a percentage of all identified phyla. Data at the family level are shown as a percentage of the total identified sequences for the families shown. 


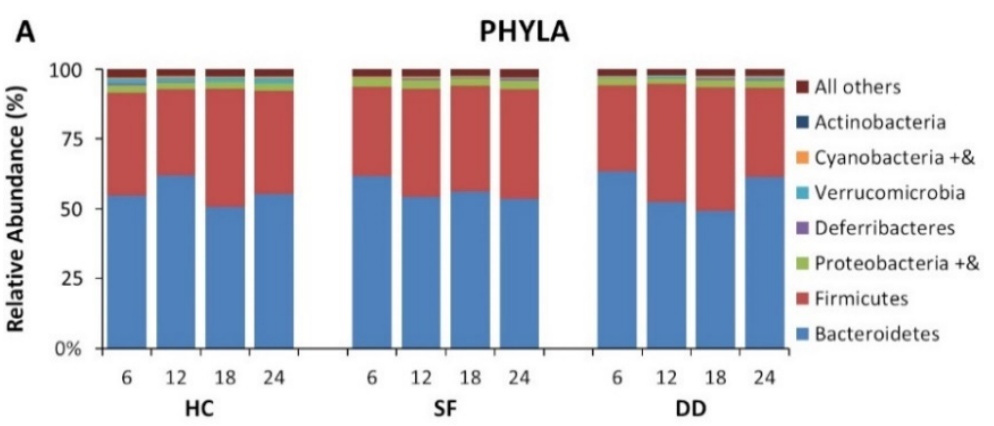

B

BACTERIODETES

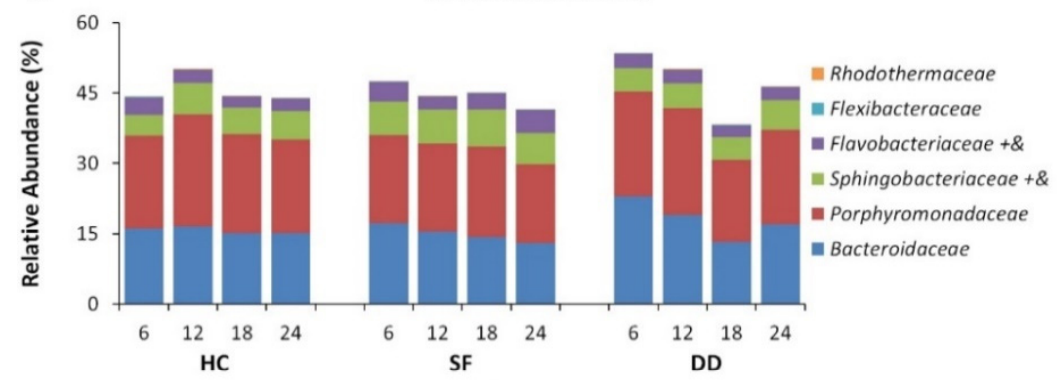

C

FIRMICUTES
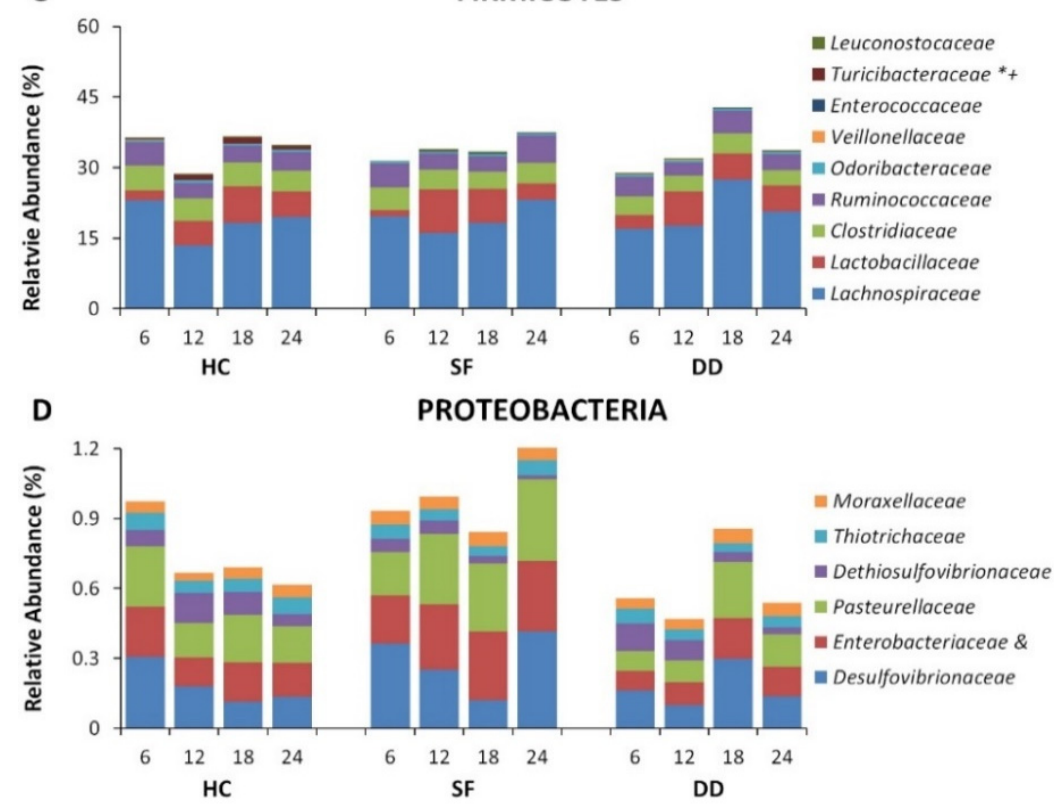

Figure 3. Relative abundance of selected microbiota after Recovery for the home cage control (HC), dark disturbed (DD) and sleep fragmented (SF) experimental groups plotted at $6 \mathrm{~h}$ sampling intervals beginning at light onset. (A) Relative abundance at the phylum level. (B) Relative abundance at the family level for Bacteroidetes. (C) Relative abundance at the family level for Firmicutes. (D) Relative abundance at the family level for Proteobacteria. Significance is indicated beside the classification name: ${ }^{*}, p<0.05$, SF compared to control;,$+ p<0.05$ DD compared to control; \&, $p<0.05$ DD compared to Light SS. All Pairwise Multiple Comparison Procedures performed using the HolmSidak method. Data at the phylum level are shown as a percentage of all identified phyla. Data at the family level are shown as a percentage of the total identified sequences for the families shown.

\subsection{Light and DD Produce Different Effects on Mucosal and Central Immune System}

To assay potential effects on mucosal immunity, we examined chemokine/cytokine expression in the MLNs which are the primary route for bacterial translocation from the gut, and the first site to show evidence of translocation $[19,20]$ (observing intestinal bacteria in the normally sterile MLN is considered direct evidence of bacterial translocation) [21-24]. 
The effects on mucosal immune function were more pronounced for SF. For example, a five-fold or greater reduction in gene expression was observed for 17 genes in SF mice, but for only four genes in DD mice (the multi-function cytokine Aimp1 was increased in DD mice). Of these, notably, CC chemokine receptor 5 (CCR5), which was highly suppressed in the MLNs after SF (Figure 4), is involved in the chemotaxis of leucocytes to inflammation sites [25] and it plays important role in the recruitment of macrophages, $\mathrm{T}$ cells, and monocytes in inflammation [26]. SF also more strongly inhibited Ccl3 (but not Ccl4 and Ccl5) expression, chemokines that signal through CCR5 [27-29]. Maraviroc, an antagonist for CCR5 used for treating HIV, selectively alters the relative abundance of gut bacteria in mice fed a high fat diet [30]. Cxcl13 was also highly suppressed by SF. This chemokine plays a significant role in the transformation of cryptopatches, produced by microbiota in the lumen, into isolated lymphoid follicles (ILFs) [31]. ILFs act as initiation sites for immunoglobulin A (IgA) responses, which in turn are important for enabling the mucosal immune system to protect against pathogens [31] and for the restoration of homeostasis in intestinal microbiota [32-34]. These factors suggest that the suppression of CCR5 and Cxcl13 in the MLNs may be relevant for mediating the effects of SF on the host-microbiota interface.

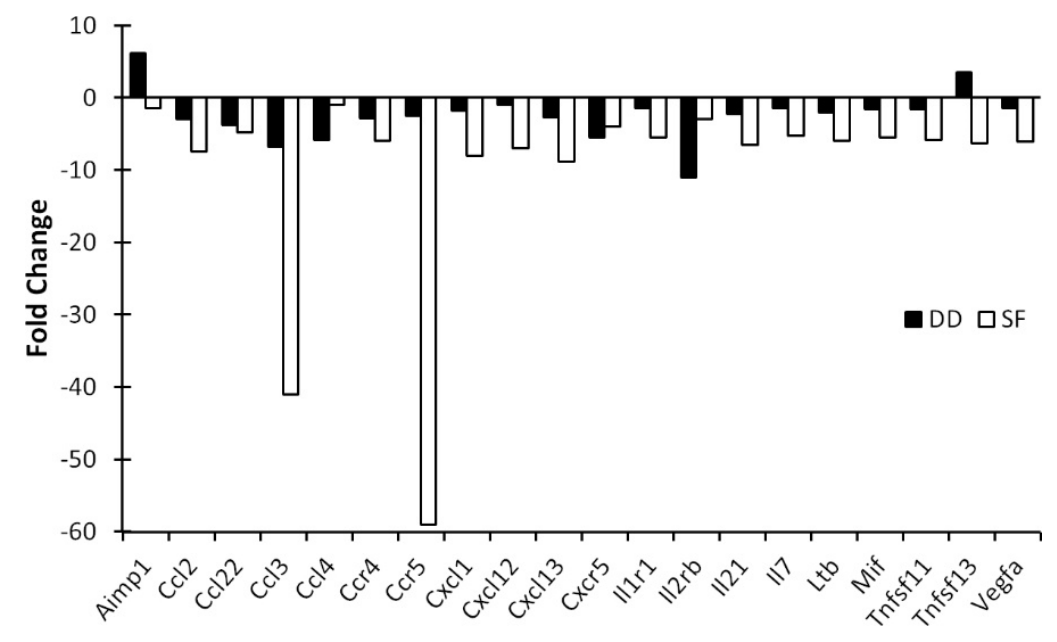

Figure 4. Ten days of SF markedly suppresses MLN cytokine gene expression. MLNs were pooled (4-5 mice/group), RNA isolated and cytokine profiles determined by qPCR array. Data are mean fold change relative to control (non-SF) mice and are plotted for chemokines and cytokines that showed a 5-fold or greater change compared to controls. SF: sleep fragmented; DD: dark disturbed.

Figure 5 presents data showing the effects of SF and DD on chemokine/cytokine expression in the cerebral cortex. Similar to gene expression profiles seen in the MLNs, SF inhibited expression of the majority of chemokine and proinflammatory cytokine genes (data not shown). However, in contrast with profiles seen in MLNs, SF induced in the cortex expression of a subset of chemokine genes (Figure 5A) as well as cytokine ligands and their receptors (Figure 5B). By comparison, DD suppressed expression of these same genes. Noteworthy among these was Ccl12/MCP-5, a structural and functional homologue of human Ccl2/MCP-1 [35] that is increased in obstructive sleep apnea syndrome [36,37], a sleep disorder characterized by SF. It plays a central role in the inflammatory process by forming a chemoattractant gradient that attracts blood-borne inflammatory cells (neutrophils, monocytes and macrophages) to transmigrate across the blood-brain barrier into the brain [38]. It is thought to coordinate cell movements during early immune response to pathogens and insults (e.g., hypoxia and ischemia) [38]. Another notable induction was the cortical alarmin, interleukin-33 (IL-33), the most potently induced cytokine gene in SF mice. IL-33, a member of the IL-1 family of proinflammatory cytokines [39,40], is released following CNS injury. It acts on astrocytes and microglia to release chemokines that recruit monocytes that promote expression of reparatory M2 macrophage genes, and appears to 
be important for CNS recovery after injury [41]. IL-33 was much less altered in DD mice compared to controls. SF and DD also differentially influenced the expression of several chemokines and cytokines in the medial prefrontal cortex (mPFC) (Figure 6). These data raise the possibility that chronic SF may lead to persistent, low-grade brain inflammation, as shown for repeated social dominance, a psychological stressor [42], at the same time that mucosal immunity is suppressed.

A.

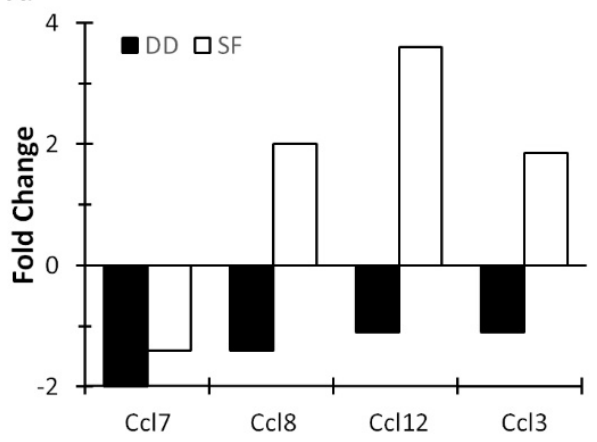

B.

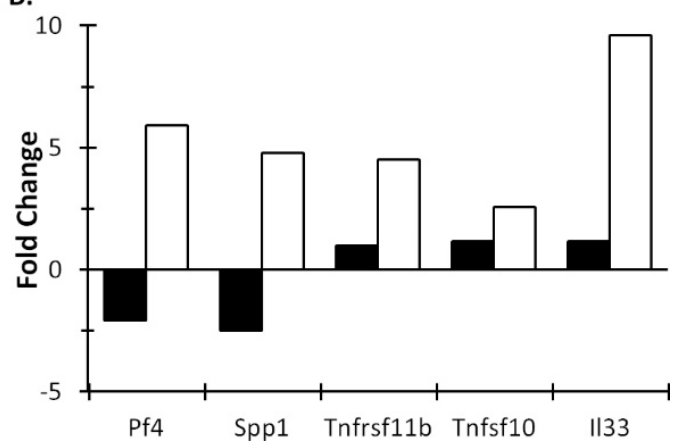

Figure 5. Differential cytokine gene activation in the cortex by SF and DD. Mice were subjected to 10 days of disturbance either during the light or dark period. Mice were then euthanized and cerebral cortex chemokine (A) and cytokine profiles (B) determined. Brain tissue for each group was pooled (4-5 mice/group), RNA isolated and cytokine profiles determined by qPCR array. Values represent changes in RNA levels relative to undisturbed mice. SF: sleep fragmented; DD: dark disturbed.

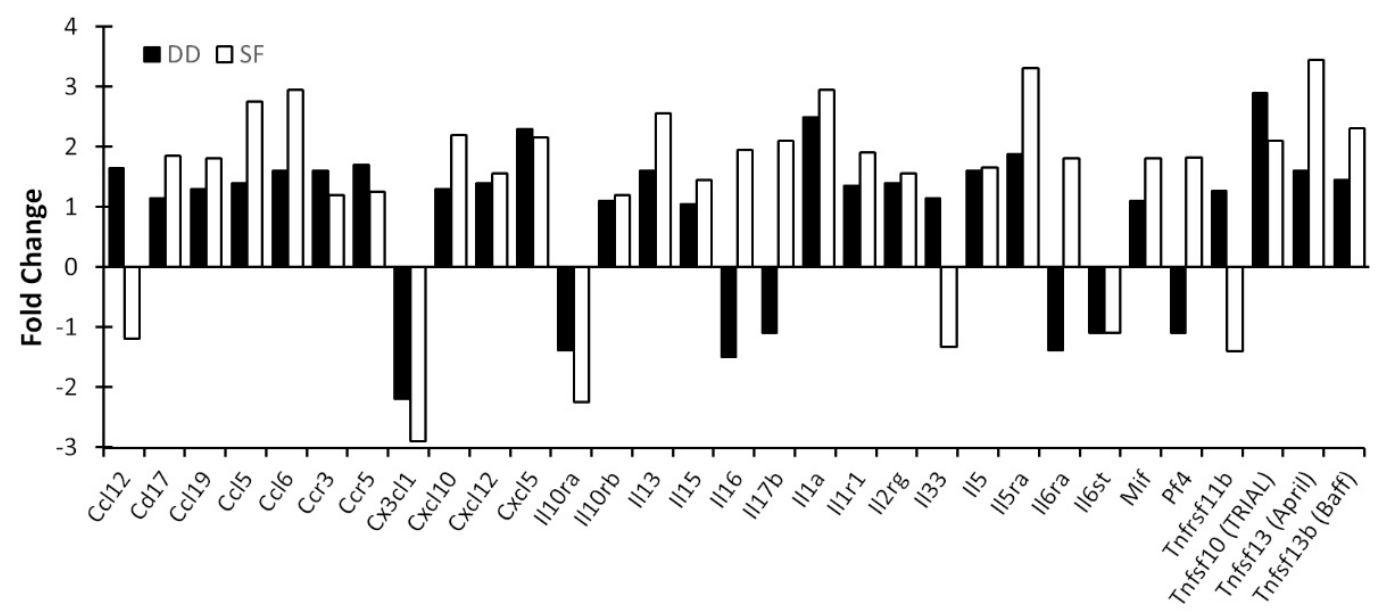

Figure 6. Cytokine gene activation in the MPFC by SF and DD. Mice were subjected to 10 days of disturbance either during the light or dark period. Mice were then euthanized and mPFC chemokine and proinflammatory cytokine profiles determined. Brain tissue for each group was pooled (4-5 mice/group), RNA isolated and cytokine profiles determined by qPCR array. Values represent changes in RNA levels relative to undisturbed mice. SF: sleep fragmented; DD: dark disturbed.

\section{Discussion}

Our data indicate that SF can significantly alter gut microbiota and differentially impact mucosal and central immune systems, and that effects can vary depending on whether disturbances were conducted in the light or dark phase. Specifically, SF suppressed important mediators of the mucosal immune system involved in maintaining the gutmicrobiota barrier at the same time that a potential neuroinflammatory response was observed in discrete brain regions. Gut microbiota also can influence brain microglia and thereby modulate innate and adaptive immune responses at mucosal surfaces, which are critical for host defense [43]. This suggests that SF, either through effects on gut microbiota and/or other pathways, has the potential to modulate the immune system in ways that 
could disturb the normal barrier between the gut and resident microbiota. This potential impact of SF is also suggested by the fact that prolonged sleep deprivation can compromise the barrier separating gut microbiota and host and allow bacterial translocation [12,13].

Reciprocal influences of sleep and the immune system have long been recognized $[13,44-47]$, and sleep disturbance has significant implications for the risk of inflammatory disease [48]. In general, sleep disturbances produce significant elevations in inflammatory markers [49-51] and sleep loss is associated with increased circulatory proinflammatory cytokines (IL-1 $\beta$, IL-6, IL-17A, TNF- $\alpha$ ) and C-reactive protein [52]. However, the interrelationships between sleep duration and inflammation are complex and can vary depending on the measure of sleep and the components of the inflammatory response that are examined [53].

Four weeks of SF in the light period has been reported to increase food intake, increase growth in Lachnospiraceae and Ruminococcaceae and decrease Lactobacillaceae families, produce systemic and visceral white adipose tissue inflammation, and to alter insulin sensitivity [16]. In our studies, we conducted an identical 2 min sweep protocol during the dark period to control for stimulation and for potential effects of induced activity. Note that the dark period manipulation may also produce some disturbances in sleep as mice also exhibit sleep during the dark period. However, the value of these two conditions is illustrated by our data which show that both light and dark manipulations produce changes in gut microbiota whereas the impact on immune responses is much more pronounced for SF.

The health impact of disturbed and deficient sleep is significant, as more than $50 \%$ of all people in the United States report difficulties with sleep or insufficient sleep at various times, whereas 50 to 70 million report having chronic sleep problems [54]. This disturbance can arise from causes including poor sleep schedules, sleep apnea, stress, and shift work. The clinical implications are profound having been linked with increased obesity, metabolic risk, coronary heart disease and stroke, altered immunity, cancers, and other common diseases [55]. Given the linkage of disturbed sleep and disease, it is not surprising that sleep is integrally related to immune system function. Sleep disturbances alter immune function and immune challenge alters sleep [44]. The reciprocal influences of sleep and the immune system have led to the suggestion that sleep is a component of the acute phase response to infection [45] and that it functions in host defense [46]. Indeed, the adverse effects of prolonged sleep deprivation are linked to host defense failure [13]. It is now becoming widely recognized that sleep loss renders an organism more susceptible to pathogens $[45,47]$ and that during infection, animals that have robust sleep responses have better prospects for survival than those that do not [46]. For instance, rabbits subjected to microbial challenge (Escherichia coli, Staphylococcus aureus, Candida albicans) have a greater chance of survival if they exhibit robust increases in non-rapid eye movement (NREM) sleep and slow wave EEG activity during NREM compared to animals that show extended periods of NREM suppression [46].

The human gastrointestinal (GI) tract alone harbors over $1 \times 10^{13}$ different microbes, a number that exceeds the number of human eukaryotic cells [56]. Recognizably, the intestinal microbiome plays a major influence human health and disease [57]. The exact role(s) these organisms play is not well understood, but evolving evidence indicates that there are interactions among the gut microbiota, the immune system, and the brain (M-G-B axis) that are critical mediators of health and disease [58]. Studies in rodents suggest that gut microbiota can modulate brain development, neurotransmitter systems, signaling pathways, synaptic related proteins, and behavior (reviewed in [1]) via immune, neural, and/or enteroendocrine mechanisms as well as by soluble factors and/or metabolites produced by bacteria [59]. Alterations in the biome balance, known as dysbiosis, contribute to immune dysregulation in the host. Mechanistically this is likely by precipitating a "proinflammatory state" via induction in changes of molecular trafficking, resulting in altered transcription cascades. Sleep disturbance-related dysbiosis upsets a key balance 
in the interaction between gut flora and the native immune system [60,61]. There are consequent related implications for immune cell activity and gut permeability [62].

Gut microbiota have also been implicated in health-related issues ranging from obesity $[58,63,64]$ to mood and anxiety disorders $[1,58,65,66]$ amongst other disorders. The gut microbiota may also interact with the stress system with implications for both development and adult responsivity to stress [2,67].

The relationship between gut microbiota and the brain is reported to be bi-directional. For example, while gut microbiota may modulate brain function, the brain may alter gut microbiota by changing gastrointestinal motility and intestinal permeability $[1,2]$. Proper functioning of the $\mathrm{M}-\mathrm{G}-\mathrm{B}$ requires the coordination of complex processes that provide a barrier (provided by the gut mucosal immune system) between tissues of the host organism and the microbes that live within the GI tract $[68,69]$. Maintaining this barrier enables the host organism to receive the benefits provided by the microbiota including promoting nutrient supply, preventing pathogen colonization, and shaping and maintaining normal mucosa immunity [70]. Failure of the barrier can result in bacterial translocation, defined as the invasion of live microbiota and/or release of their toxins into the MLNs and/or other organs outside the intestines [19]. Though a certain amount of bacterial translocation occurs in healthy humans and animals [19], excessive amounts can lead to the increased risk of sepsis, dysbiosis, cancer, and/or autoimmunity [68] and organ dysfunction and failure [70].

A limitation of our study is that we did not record sleep and, thus, we could not directly assess the changes in sleep architecture that were associated with time under SF. However, we specifically chose to conduct this initial study in non-implanted mice because the procedures necessary for recording sleep via cabling has the potential to impact sleep amounts and activity [71] and recording via telemetry in mice generally requires intraperitoneal implants which would have the potential to alter intestine function [72]. Studies incorporating recording sleep will be needed in the future to fully assess the relationship between sleep changes and alterations in the microbiome and immune markers, but they will need to consider the potential effects of the recording methods that are used. Additionally, assessing changes in the microbiome on different SF schedules and durations will be useful. We conducted our study with ten days of SF and effects have been reported for longer periods [16]. By comparison, Zhang et al. did not find strong evidence of dysbiosis following five days of sleep restriction in rats [73], suggesting that shorter periods of sleep disruption may have fewer observable effects. A last limitation is that the data we present on chemokine and cytokine expression in the MLNs and brain are on pooled samples which may not fully and accurately characterize the changes induced by SF. However, these data should provide a guide for issues that need to be considered in assessing the role of sleep in mediating $\mathrm{M}-\mathrm{G}-\mathrm{B}$ interactions, i.e., sleep disruptions can have effects at multiple points along the M-G-B axis that could play roles in the effects of the microbiome on health and function. They also provide suggestions for chemokines and cytokines that may play roles in regulating $\mathrm{M}-\mathrm{G}-\mathrm{B}$ interactions.

Various studies have demonstrated a relationship between sleep disturbances and gut microbiota that appear to have relevance for health $[3-6,61,74,75]$. However, the effects of sleep disruption are complex as it also has a significant interaction with the immune system (e.g., [7-11]) that would have the potential to alter the effects of the gut microbiota, possibly by impact on the immune processes that maintain the barrier between host tissue and the microbiota and/or functioning of the central nervous system. An extreme example of this is found in animals experiencing prolonged, experimental sleep deprivation. Sustained sleep deprivation promotes bacterial translocation [12], and death that can occur after prolonged sleep deprivation in animals has been attributed to bloodstream infection by opportunistic anaerobic bacteria that normally are contained within the gut [13]. Bloodstream infection is also a leading cause of death in critically ill patients [76]. Thus, while experimental prolonged sleep deprivation does not fully model sleep disturbances common in modern life, the recognized effects of sleep deficiency 
and increasing recognition of the role that the gut microbiota play in mediating immune function suggest that delineating the interactions among disturbed sleep, the immune system and gut microbiota will be critical for understanding their role in health and disease. Mitigation strategies directed at optimizing sleep functionality to maintain health or direct disease-related interventions are potential translational opportunities.

Author Contributions: Conceptualization, L.D.S., R.P.C. and D.A.J.; methodology, L.D.S., R.P.C. and D.A.J.; validation, L.D.S., R.P.C. and D.A.J.; formal analysis, L.D.S., R.P.C. and L.L.W.; investigation, L.L.W., E.C.O.IV, R.S. and J.L.C.; resources, L.D.S., R.P.C. and D.A.J.; data curation, L.L.W.; writingoriginal draft preparation, L.D.S.; writing-review and editing, R.P.C., D.A.J., L.L.W., E.C.O.IV, R.S. and J.L.C.; visualization, L.D.S., R.P.C. and L.L.W.; supervision, L.D.S., R.P.C. and D.A.J.; project administration, L.D.S. and L.L.W.; funding acquisition, L.D.S., R.P.C. and D.A.J.; All authors have read and agreed to the published version of the manuscript.

Funding: EVMS institutional funds.

Institutional Review Board Statement: All procedures were conducted in accordance with the National Institutes of Health Guide for the Care and Use of Experimental Animals and were approved by Eastern Virginia Medical School's Institutional Animal Care and Use Committee (protocol 17-015, approved 15 September 2017).

Informed Consent Statement: Not applicable.

Data Availability Statement: Experimental data available upon request.

Conflicts of Interest: The authors declare no conflict of interest. The funders had no role in the design of the study; in the collection, analyses, or interpretation of data; in the writing of the manuscript, or in the decision to publish the results.

\section{References}

1. Mayer, E.A.; Knight, R.; Mazmanian, S.K.; Cryan, J.F.; Tillisch, K. Gut microbes and the brain: Paradigm shift in neuroscience. J. Neurosci. 2014, 34, 15490-15496. [CrossRef] [PubMed]

2. Carabotti, M.; Scirocco, A.; Maselli, M.A.; Severi, C. The gut-brain axis: Interactions between enteric microbiota, central and enteric nervous systems. Ann. Gastroenterol. Quart. Publ. Hell. Soc. Gastroenterol. 2015, 28, 203-209.

3. Durgan, D.J.; Ganesh, B.P.; Cope, J.L.; Ajami, N.J.; Phillips, S.C.; Petrosino, J.F.; Hollister, E.B.; Bryan, R.M., Jr. Role of the gut microbiome in obstructive sleep apnea-induced hypertension. Hypertension 2016, 67, 469-474. [CrossRef]

4. Jackson, M.L.; Butt, H.; Ball, M.; Lewis, D.P.; Bruck, D. Sleep quality and the treatment of intestinal microbiota imbalance in Chronic Fatigue Syndrome: A pilot study. Sleep Sci. 2015, 8, 124-133. [CrossRef]

5. Thaiss, C.A.; Zeevi, D.; Levy, M.; Zilberman-Schapira, G.; Suez, J.; Tengeler, A.C.; Abramson, L.; Katz, M.N.; Korem, T.; Zmora, N.; et al. Transkingdom control of microbiota diurnal oscillations promotes metabolic homeostasis. Cell 2014, 159, 514-529. [CrossRef]

6. Benedict, C.; Vogel, H.; Jonas, W.; Woting, A.; Blaut, M.; Schurmann, A.; Cedernaes, J. Gut microbiota and glucometabolic alterations in response to recurrent partial sleep deprivation in normal-weight young individuals. Mol. Metab. 2016, 5, 1175-1186. [CrossRef] [PubMed]

7. Ramesh, V.; Nair, D.; Zhang, S.X.; Hakim, F.; Kaushal, N.; Kayali, F.; Wang, Y.; Li, R.C.; Carreras, A.; Gozal, D. Disrupted sleep without sleep curtailment induces sleepiness and cognitive dysfunction via the tumor necrosis factor-alpha pathway. $J$. Neuroinflamm. 2012, 9, 91. [CrossRef]

8. Hakim, F.; Wang, Y.; Zhang, S.X.; Zheng, J.; Yolcu, E.S.; Carreras, A.; Khalyfa, A.; Shirwan, H.; Almendros, I.; Gozal, D. Fragmented sleep accelerates tumor growth and progression through recruitment of tumor-associated macrophages and TLR4 signaling. Cancer Res. 2014, 74, 1329-1337. [CrossRef] [PubMed]

9. Gozal, D.; Almendros, I.; Hakim, F. Sleep apnea awakens cancer: A unifying immunological hypothesis. Oncoimmunology 2014, 3, e28326. [CrossRef] [PubMed]

10. Trammell, R.A.; Verhulst, S.; Toth, L.A. Effects of sleep fragmentation on sleep and markers of inflammation in mice. Comp. Med. 2014, 64, 13-24. [PubMed]

11. Trammell, R.A.; Toth, L.A. Behavioral perturbation and sleep in healthy and virus-infected inbred mice. Comp. Med. 2014, 64, 283-292.

12. Everson, C.A.; Toth, L.A. Systemic bacterial invasion induced by sleep deprivation. Am. J. Physiol. Regul. Integr. Comp. Physiol. 2000, 278, R905-R916. [CrossRef]

13. Everson, C.A. Sustained sleep deprivation impairs host defense. Am. J. Physiol. 1993, 265, R1148-R1154. [CrossRef]

14. Mezick, E.J.; Matthews, K.A.; Hall, M.; Kamarck, T.W.; Buysse, D.J.; Owens, J.F.; Reis, S.E. Intra-individual variability in sleep duration and fragmentation: Associations with stress. Psychoneuroendocrinology 2009, 34, 1346-1354. [CrossRef] 
15. Miller, M.A. The role of sleep and sleep disorders in the development, diagnosis, and management of neurocognitive disorders. Front. Neurol. 2015, 6, 224. [CrossRef] [PubMed]

16. Poroyko, V.A.; Carreras, A.; Khalyfa, A.; Khalyfa, A.A.; Leone, V.; Peris, E.; Almendros, I.; Gileles-Hillel, A.; Qiao, Z.; Hubert, N.; et al. Chronic sleep disruption alters gut microbiota, induces systemic and adipose tissue inflammation and insulin resistance in mice. Sci. Rep. 2016, 6, 35405. [CrossRef] [PubMed]

17. Nair, D.; Zhang, S.X.; Ramesh, V.; Hakim, F.; Kaushal, N.; Wang, Y.; Gozal, D. Sleep fragmentation induces cognitive deficits via nicotinamide adenine dinucleotide phosphate oxidase-dependent pathways in mouse. Am. J. Respir. Crit. Care Med. 2011, 184, 1305-1312. [CrossRef] [PubMed]

18. Wang, Y.; Carreras, A.; Lee, S.; Hakim, F.; Zhang, S.X.; Nair, D.; Ye, H.; Gozal, D. Chronic sleep fragmentation promotes obesity in young adult mice. Obesity 2014, 22, 758-762. [CrossRef]

19. Balzan, S.; de Almeida Quadros, C.; de Cleva, R.; Zilberstein, B.; Cecconello, I. Bacterial translocation: Overview of mechanisms and clinical impact. J. Gastroenterol. Hepatol. 2007, 22, 464-471. [CrossRef]

20. Deitch, E.A. Bacterial translocation or lymphatic drainage of toxic products from the gut: What is important in human beings? Surgery 2002, 131, 241-244. [CrossRef]

21. O'Boyle, C.J.; MacFie, J.; Mitchell, C.J.; Johnstone, D.; Sagar, P.M.; Sedman, P.C. Microbiology of bacterial translocation in humans. Gut 1998, 42, 29-35. [CrossRef]

22. O'Boyle, C.J.; MacFie, J.; Dave, K.; Sagar, P.S.; Poon, P.; Mitchell, C.J. Alterations in intestinal barrier function do not predispose to translocation of enteric bacteria in gastroenterologic patients. Nutrition 1998, 14, 358-362. [CrossRef]

23. Magnotti, L.J.; Upperman, J.S.; Xu, D.Z.; Lu, Q.; Deitch, E.A. Gut-derived mesenteric lymph but not portal blood increases endothelial cell permeability and promotes lung injury after hemorrhagic shock. Ann. Surg. 1998, 228, 518-527. [CrossRef]

24. Woodcock, N.P.; Robertson, J.; Morgan, D.R.; Gregg, K.L.; Mitchell, C.J.; MacFie, J. Bacterial translocation and immunohistochemical measurement of gut immune function. J. Clin. Pathol. 2001, 54, 619-623. [CrossRef] [PubMed]

25. Proost, P.; Wuyts, A.; van Damme, J. The role of chemokines in inflammation. Int. J. Clin. Lab. Res. 1996, 26, 211-223. [CrossRef]

26. Spagnolo, P.; Renzoni, E.A.; Wells, A.U.; Copley, S.J.; Desai, S.R.; Sato, H.; Grutters, J.C.; Abdallah, A.; Taegtmeyer, A.; du Bois, R.M.; et al. C-C chemokine receptor 5 gene variants in relation to lung disease in sarcoidosis. Am. J. Respir. Crit. Care Med. 2005, 172, 721-728. [CrossRef]

27. Samson, M.; Labbe, O.; Mollereau, C.; Vassart, G.; Parmentier, M. Molecular cloning and functional expression of a new human CC-chemokine receptor gene. Biochemistry 1996, 35, 3362-3367. [CrossRef] [PubMed]

28. Raport, C.J.; Gosling, J.; Schweickart, V.L.; Gray, P.W.; Charo, I.F. Molecular cloning and functional characterization of a novel human CC chemokine receptor (CCR5) for RANTES, MIP-1beta, and MIP-1alpha. J. Biol. Chem. 1996, 271, 17161-17166. [CrossRef] [PubMed]

29. Combadiere, C.; Ahuja, S.K.; Tiffany, H.L.; Murphy, P.M. Cloning and functional expression of CC CKR5, a human monocyte CC chemokine receptor selective for MIP-1(alpha), MIP-1(beta), and RANTES. J. Leukoc. Biol. 1996, 60, 147-152. [CrossRef] [PubMed]

30. Perez-Matute, P.; Perez-Martinez, L.; Aguilera-Lizarraga, J.; Blanco, J.R.; Oteo, J.A. Maraviroc modifies gut microbiota composition in a mouse model of obesity: A plausible therapeutic option to prevent metabolic disorders in HIV-infected patients. Publ. Soc. Esp. Quimioter. 2015, 28, 200-206.

31. McDonald, K.G.; McDonough, J.S.; Dieckgraefe, B.K.; Newberry, R.D. Dendritic cells produce CXCL13 and participate in the development of murine small intestine lymphoid tissues. Am. J. Pathol. 2010, 176, 2367-2377. [CrossRef] [PubMed]

32. Suzuki, K.; Meek, B.; Doi, Y.; Muramatsu, M.; Chiba, T.; Honjo, T.; Fagarasan, S. Aberrant expansion of segmented filamentous bacteria in IgA-deficient gut. Proc. Natl. Acad. Sci. USA 2004, 101, 1981-1986. [CrossRef] [PubMed]

33. Fagarasan, S.; Honjo, T. Regulation of IgA synthesis at mucosal surfaces. Curr. Opin. Immunol. 2004, 16, 277-283. [CrossRef] [PubMed]

34. Bouskra, D.; Brezillon, C.; Berard, M.; Werts, C.; Varona, R.; Boneca, I.G.; Eberl, G. Lymphoid tissue genesis induced by commensals through NOD1 regulates intestinal homeostasis. Nature 2008, 456, 507-510. [CrossRef] [PubMed]

35. Sarafi, M.N.; Garcia-Zepeda, E.A.; MacLean, J.A.; Charo, I.F.; Luster, A.D. Murine monocyte chemoattractant protein (MCP)-5: A novel CC chemokine that is a structural and functional homologue of human MCP-1. J. Exp. Med. 1997, 185, 99-109. [CrossRef]

36. Ohga, E.; Tomita, T.; Wada, H.; Yamamoto, H.; Nagase, T.; Ouchi, Y. Effects of obstructive sleep apnea on circulating ICAM-1, IL-8, and MCP-1. J. Appl. Physiol. 2003, 94, 179-184. [CrossRef]

37. Kim, J.; Lee, C.H.; Park, C.S.; Kim, B.G.; Kim, S.W.; Cho, J.H. Plasma levels of MCP-1 and adiponectin in obstructive sleep apnea syndrome. Arch. Otolaryngol.-Head Neck Surg. 2010, 136, 896-899. [CrossRef] [PubMed]

38. Mojsilovic-Petrovic, J.; Callaghan, D.; Cui, H.; Dean, C.; Stanimirovic, D.B.; Zhang, W. Hypoxia-inducible factor-1 (HIF-1) is involved in the regulation of hypoxia-stimulated expression of monocyte chemoattractant protein-1 (MCP-1/CCL2) and MCP-5 (Ccl12) in astrocytes. J. Neuroinflamm. 2007, 4, 12. [CrossRef]

39. Liew, F.Y.; Girard, J.P.; Turnquist, H.R. Interleukin-33 in health and disease. Nat. Rev. Immunol. 2016, 16, 676-689. [CrossRef]

40. Liew, F.Y. IL-33: A Janus cytokine. Ann. Rheum. Dis. 2012, 71 (Suppl. 2), i101-i104. [CrossRef] [PubMed]

41. Gadani, S.P.; Walsh, J.T.; Smirnov, I.; Zheng, J.; Kipnis, J. The glia-derived alarmin IL-33 orchestrates the immune response and promotes recovery following CNS injury. Neuron 2015, 85, 703-709. [CrossRef]

42. Wohleb, E.S.; Powell, N.D.; Godbout, J.P.; Sheridan, J.F. Stress-induced recruitment of bone marrow-derived monocytes to the brain promotes anxiety-like behavior. J. Neurosci. Off. J. Soc. Neurosci. 2013, 33, 13820-13833. [CrossRef] 
43. Erny, D.; Hrabe de Angelis, A.L.; Jaitin, D.; Wieghofer, P.; Staszewski, O.; David, E.; Keren-Shaul, H.; Mahlakoiv, T.; Jakobshagen, K.; Buch, T.; et al. Host microbiota constantly control maturation and function of microglia in the CNS. Nat. Neurosci. 2015, 18, 965-977. [CrossRef]

44. Opp, M.R. Sleeping to fuel the immune system: Mammalian sleep and resistance to parasites. BMC Evol. Biol. 2009, 9, 8. [CrossRef]

45. Krueger, J.M.; Majde, J.A. Sleep as a host defense: Its regulation by microbial products and cytokines. Clin. Immunol. Immunopathol. 1990, 57, 188-199. [CrossRef]

46. Toth, L.A.; Tolley, E.A.; Krueger, J.M. Sleep as a prognostic indicator during infectious disease in rabbits. Proc. Soc. Exp. Biol. Med. 1993, 203, 179-192. [CrossRef] [PubMed]

47. Krueger, J.M.; Karnovsky, M.L. Sleep as a neuroimmune phenomenon: A brief historical perspective. Adv. Neuroimmunol. 1995, 5, 5-12. [CrossRef]

48. Irwin, M.R.; Opp, M.R. Sleep health: Reciprocal regulation of sleep and innate immunity. Neuropsychopharmacol. Off. Publ. Am. Coll. Neuropsychopharmacol. 2017, 42, 129-155. [CrossRef]

49. Mullington, J.M.; Simpson, N.S.; Meier-Ewert, H.K.; Haack, M. Sleep loss and inflammation. Best practice \& research. Clin. Endocrinol. Metab. 2010, 24, 775-784. [CrossRef]

50. Haack, M.; Sanchez, E.; Mullington, J.M. Elevated inflammatory markers in response to prolonged sleep restriction are associated with increased pain experience in healthy volunteers. Sleep 2007, 30, 1145-1152. [CrossRef]

51. Opp, M.R.; George, A.; Ringgold, K.M.; Hansen, K.M.; Bullock, K.M.; Banks, W.A. Sleep fragmentation and sepsis differentially impact blood-brain barrier integrity and transport of tumor necrosis factor-alpha in aging. Brain Behav. Immun. 2015, 50, 259-265. [CrossRef] [PubMed]

52. Hurtado-Alvarado, G.; Pavon, L.; Castillo-Garcia, S.A.; Hernandez, M.E.; Dominguez-Salazar, E.; Velazquez-Moctezuma, J.; Gomez-Gonzalez, B. Sleep loss as a factor to induce cellular and molecular inflammatory variations. Clin. Dev. Immunol. 2013, 2013, 801341. [CrossRef]

53. Patel, S.R.; Zhu, X.; Storfer-Isser, A.; Mehra, R.; Jenny, N.S.; Tracy, R.; Redline, S. Sleep duration and biomarkers of inflammation. Sleep 2009, 32, 200-204. [CrossRef] [PubMed]

54. Institute of Medicine (US) Committee on Sleep Medicine and Research. Sleep Disorders and Sleep Deprivation: An Unmet Public Health Problem; National Academies Press (US): Washington, DC, USA, 2006.

55. Luyster, F.S.; Strollo, P.J., Jr.; Zee, P.C.; Walsh, J.K. Sleep: A health imperative. Abstract Supplement. Sleep 2012, 35, 727-734. [CrossRef]

56. Qin, J.; Li, R.; Raes, J.; Arumugam, M.; Burgdorf, K.S.; Manichanh, C.; Nielsen, T.; Pons, N.; Levenez, F.; Yamada, T.; et al. A human gut microbial gene catalogue established by metagenomic sequencing. Nature 2010, 464, 59-65. [CrossRef]

57. Young, V.B. The intestinal microbiota in health and disease. Curr. Opin. Gastroenterol. 2012, 28, 63-69. [CrossRef]

58. Cryan, J.F.; Dinan, T.G. Mind-altering microorganisms: The impact of the gut microbiota on brain and behaviour. Nat. Rev. Neurosci. 2012, 13, 701-712. [CrossRef]

59. Wang, Y.; Kasper, L.H. The role of microbiome in central nervous system disorders. Brain Behav. Immun. 2014, 38, 1-12. [CrossRef]

60. Krueger, J.M.; Opp, M.R. Sleep and microbes. Int. Rev. Neurobiol. 2016, 131, 207-225. [CrossRef]

61. Parekh, P.J.; Oldfield, E.C.T.; Johnson, D.A. The effects of sleep on the commensal microbiota: Eyes wide open? J. Clin. Gastroenterol. 2018, 52, 204-209. [CrossRef] [PubMed]

62. Dimitrov, S.; Benedict, C.; Heutling, D.; Westermann, J.; Born, J.; Lange, T. Cortisol and epinephrine control opposing circadian rhythms in T cell subsets. Blood 2009, 113, 5134-5143. [CrossRef]

63. Conterno, L.; Fava, F.; Viola, R.; Tuohy, K.M. Obesity and the gut microbiota: Does up-regulating colonic fermentation protect against obesity and metabolic disease? Genes Nutr. 2011, 6, 241-260. [CrossRef] [PubMed]

64. Million, M.; Lagier, J.C.; Yahav, D.; Paul, M. Gut bacterial microbiota and obesity. Clin. Microbiol. Infect. Off. Publ. Eur. Soc. Clin. Microbiol. Infect. Dis. 2013, 19, 305-313. [CrossRef]

65. Gonzalez, A.; Stombaugh, J.; Lozupone, C.; Turnbaugh, P.J.; Gordon, J.I.; Knight, R. The mind-body-microbial continuum. Dialogues Clin. Neurosci. 2011, 13, 55-62. [PubMed]

66. Dinan, T.G.; Cryan, J.F. The microbiome-gut-brain axis in health and disease. Gastroenterol. Clin. N. Am. 2017, 46, 77-89. [CrossRef]

67. Dinan, T.G.; Cryan, J.F. Regulation of the stress response by the gut microbiota: Implications for psychoneuroendocrinology. Psychoneuroendocrinology 2012, 37, 1369-1378. [CrossRef]

68. Runtsch, M.C.; Hu, R.; Alexander, M.; Wallace, J.; Kagele, D.; Petersen, C.; Valentine, J.F.; Welker, N.C.; Bronner, M.P.; Chen, X.; et al. MicroRNA-146a constrains multiple parameters of intestinal immunity and increases susceptibility to DSS colitis. Oncotarget 2015, 6, 28556-28572. [CrossRef]

69. Baumgart, D.C.; Dignass, A.U. Intestinal barrier function. Curr. Opin. Clin. Nutr. Metab. Care 2002, 5, 685-694. [CrossRef]

70. Chen, Y.X.; Lai, L.N.; Zhang, H.Y.; Bi, Y.H.; Meng, L.; Li, X.J.; Tian, X.X.; Wang, L.M.; Fan, Y.M.; Zhao, Z.F.; et al. Effect of artesunate supplementation on bacterial translocation and dysbiosis of gut microbiota in rats with liver cirrhosis. World J. Gastroenterol. 2016, 22, 2949-2959. [CrossRef]

71. Tang, X.; Orchard, S.M.; Liu, X.; Sanford, L.D. Effect of varying recording cable weight and flexibility on activity and sleep in mice. Sleep 2004, 27, 803-810. [PubMed]

72. Tang, X.; Sanford, L.D. Telemetric recording of sleep and home cage activity in mice. Sleep 2002, 25, 691-699. [CrossRef] [PubMed] 
73. Zhang, S.L.; Bai, L.; Goel, N.; Bailey, A.; Jang, C.J.; Bushman, F.D.; Meerlo, P.; Dinges, D.F.; Sehgal, A. Human and rat gut microbiome composition is maintained following sleep restriction. Proc. Natl. Acad. Sci. USA 2017, 114, E1564-E1571. [CrossRef] [PubMed]

74. Parekh, P.J.; Oldfield, E.C.t.; Johnson, D.A. Wake-up call to clinicians: The impact of sleep dysfunction on gastrointestinal health and disease. J. Clin. Gastroenterol. 2018, 52, 194-203. [CrossRef]

75. Sanford, L.D.; Ciavarra, R.P. Sleep, immune function, and the gut microbiome: Pathophysiologic translational implications. In Sleep Effect on Gastrointestinal Health and Disease: Opportunities for Promoting Health and Optimizing Disease Management; Johnson, D.A., Orr, W.C., Ware, J.C., Eds.; Nova Science Publishers: Hauppauge, NY, USA, 2018; pp. 17-40.

76. Decuypere, S.; Meehan, C.J.; Van Puyvelde, S.; De Block, T.; Maltha, J.; Palpouguini, L.; Tahita, M.; Tinto, H.; Jacobs, J.; Deborggraeve, S. Diagnosis of bacterial bloodstream infections: A 16S metagenomics approach. PLoS Negl. Trop. Dis. 2016, 10, e0004470. [CrossRef] [PubMed] 